\title{
HYDROGEN-PLASTICITY INTERACTIONS IN PEARLITIC STEEL: A FRACTOGRAPHIC AND NUMERICAL STUDY
}

\author{
J. Toribio and V. Kharin \\ Department of Materials Engineering, University of Salamanca \\ E.P.S., Campus Viriato, Avda. Requejo 33, 49022 Zamora, Spain \\ Tel: (34-980) 5450 00; Fax: (34-980) 5450 02, E-mail: toribio@usal.es
}

\begin{abstract}
This paper analyzes by numerical methods the plastic zone evolution in the vicinity of a crack tip in a high-strength pearlitic steel subjected to cyclic (fatigue) precracking and posterior hydrogen assisted cracking (HAC). The plastic zone extent is compared with the tearing topography surface (TTS) or hydrogen-assisted micro-damage region in the experiments. Results demonstrate that the TTS depth has no relation with the active plastic zone dimension, i.e., with the size of the only region in which there is dislocation movement, so hydrogen transport cannot be attributed to dislocation dragging, but to random-walk lattice diffusion in which the hydrostatic stress field plays a relevant role.
\end{abstract}

\section{Introduction}

In hydrogen assisted cracking (HAC) processes, a basic issue is to elucidate the main hydrogen transport mechanism. Two main types of hydrogen transport in metals have been proposed: (i) lattice diffusion or random-walk diffusion, described by Troiano [1], Van Leeuwen [2] and Toribio and Kharin [3]; (ii) dislocation sweeping or dislocation dragging, described by Tien et al. [4]; Johnson and Hirth [5] and Nair et al. [6]. This second mechanism is associated with hydrogen-plasticity interactions.

Diffusion is a transport mode by which hydrogen moves towards the points of minimum concentration through the crystalline lattice in the form of random-walk governed by the $(\mathrm{Dt})^{1 / 2}$ term which controls the penetration distance [1]. When stress-assisted diffusion is considered [2,3] hydrogen movement is driven by the gradients of both concentration and hydrostatic stress. A mechanism of hydrogen transport based on lattice diffusion is consistent with the results of slow strain rate tests under cathodic polarization environmental conditions, since it predicts maximum embrittlement at the slowest strain rates. On the other hand, diffusion is usually a slow transport mode and penetration distances are rather small.

Dislocation sweeping is a transport mode by which hydrogen is dragged by dislocations as the plastic zone spreads. This may be associated with the average velocity of dislocations and expressed in terms of the plastic strain rate. There are two main models to evaluate the possible supersaturation or enrichment of hydrogen at specific sites in the material as a result of a dislocation sweep-in of hydrogen: the stripping model by Tien et al. [4] and the annihilation model by Johnson and Hirth [5] both reviewed by Nair et al. [6]. The first estimates a significant build-up of hydrogen, while the latter concludes that the kinetic supersaturations are extremely small in all real situations. The weakest point of the two models is their inconsistency with the well known experimental evidence of the inverse dependence of hydrogen embrittlement upon strain rate. The stripping model predicts maximum hydrogen embrittlement at an intermediate strain rate, whereas according to the annihilation model the kinetic supersaturation is proportional to the strain rate. 
This paper tries to provide more insight into this fundamental question related to hydrogen-plasticity interactions. To this end, tests with precracked specimens of highstrength pearlitic steel are analyzed in combination with a high resolution numerical modelling of the plastic zone evolution in the vicinity of the crack tip subjected to fatigue precracking and subsequent monotonous loading up to the points of fracture in the HAC tests.

\section{Experimental}

A high strength eutectoid steel was used in this work. The chemical composition is given in Table 1 and the mechanical properties in Table 2. To evaluate the HAC behaviour of the steel, slow strain rate tests were performed on transversely precracked rods immersed in aqueous solution under electrochemical control, as described by Toribio and Lancha [7]. The electrochemical potential (constant during the tests) was $\mathrm{E}=-1200 \mathrm{mV} \mathrm{SCE}$ (cathodic) to promote HAC in the metallic specimens.

TABLE 1. Chemical composition (wt \%) of the steel.

\begin{tabular}{|c|c|c|c|c|c|c|c|}
\hline $\mathrm{C}$ & $\mathrm{Mn}$ & $\mathrm{Si}$ & $\mathrm{P}$ & $\mathrm{S}$ & $\mathrm{Cr}$ & $\mathrm{Ni}$ & $\mathrm{Mo}$ \\
\hline 0.74 & 0.70 & 0.20 & 0.016 & 0.023 & 0.01 & 0.01 & 0.001 \\
\hline
\end{tabular}

TABLE 2. Mechanical properties of the steel.

\begin{tabular}{|c|c|c|c|c|c|c|}
\hline $\mathrm{E}(\mathrm{GPa})$ & $\sigma_{\mathrm{Y}}(\mathrm{MPa})$ & $\mathrm{K}_{\mathrm{IC}}\left(\mathrm{MPam}^{1 / 2}\right)$ & $\mathrm{P}_{\mathrm{I}}(\mathrm{MPa})$ & $\mathrm{n}_{\mathrm{I}}$ & $\mathrm{P}_{\mathrm{II}}(\mathrm{MPa})$ & $\mathrm{n}_{\mathrm{II}}$ \\
\hline 195 & 725 & 53 & 2120 & 5.8 & 2160 & 17 \\
\hline
\end{tabular}

E: Young's modulus; $\sigma_{\mathrm{Y}}$ : Tensile yield stress; $\mathrm{K}_{\mathrm{IC}}$ : Fracture toughness

Ramberg-Osgood curve $\varepsilon=\sigma / \mathrm{E}+(\sigma / \mathrm{P})^{\mathrm{n}}$; Part I: $\varepsilon \mathrm{P} \leq 1.07$; Part II: $\varepsilon \mathrm{P}>1.07$

Precracking was carried out by axial fatigue in air environment. Various series of samples were prepared by using different fatigue loads during the last stage of fatigue precracking just previous to the environmentally assisted fracture test so as to control this important experimental variable which clearly influences the results in HAC, cf. [7]. The maximum stress intensity factor (SIF or $K$ ) levels during fatigue (last stage) were $K_{\max }=0.28,0.45$, 0.60 and $0.80 \mathrm{~K}_{\mathrm{IC}}$.

Fig. 1 shows the experimental device (three-electrode assembly) and the main results expressed in terms of the failure load in a hydrogen environment $\mathrm{F}_{\mathrm{HAC}}$ (divided by the value in air $\mathrm{F}_{\mathrm{C}}$ ) as a function of $\mathrm{K}_{\max } / \mathrm{K}_{\mathrm{IC}}$. The effect of fatigue precracking is beneficial for the HAC resistance, since $F_{H A C}$ is an increasing function of $K_{\text {max }}$. This may be caused by the cyclic plastic zone or the compressive residual stresses near the crack tip which is prestrained (or prestressed) by fatigue: the higher the cyclic load level, the more pronounced the prestraining/prestressing effect which delays the hydrogen entry and improves material performance in the hostile environment.

The fractographic analysis showed a special fracture mode between the fatigue precrack and the final cleavage fracture: the tearing topography surface or TTS describe by Thompson and Chesnutt [8] and Costa and Thompson [9] and shown in Fig. 2. It can be considered as the hydrogen-assisted micro-damage region, as shown by Toribio [10]. Its depth was 
measured at the deepest point of the crack, in direction perpendicular to the crack front over the fracture surface (crack plane). Results are given in Fig. 2, showing an inverse relationship between the TTS depth and the maximum stress intensity level during the last stage of fatigue precracking $\left(\mathrm{K}_{\max }\right)$, i.e., the stronger the fatigue precracking, the shallower the TTS region in the vicinity of the crack tip.
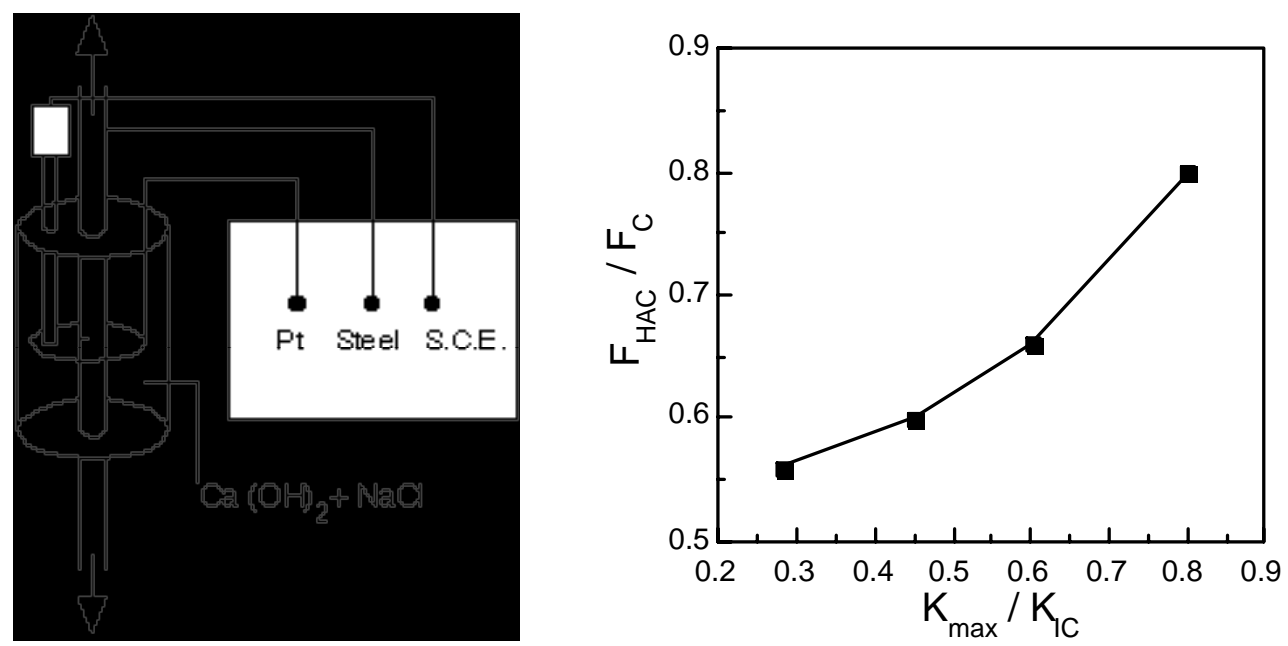

FIGURE 1. Experimental device consisting of a three-electrode assembly with a working electrode (steel precracked wire), a reference electrode (saturated calomel electrode: S.C.E.) and a platinum counter-electrode (Pt), together with the main experimental results given in terms of the failure load in a hydrogen environment $\mathrm{F}_{\mathrm{HAC}}$ (divided by the value in air $\mathrm{F}_{\mathrm{C}}$ ) as a function of $\mathrm{K}_{\max } / \mathrm{K}_{\mathrm{IC}}$.
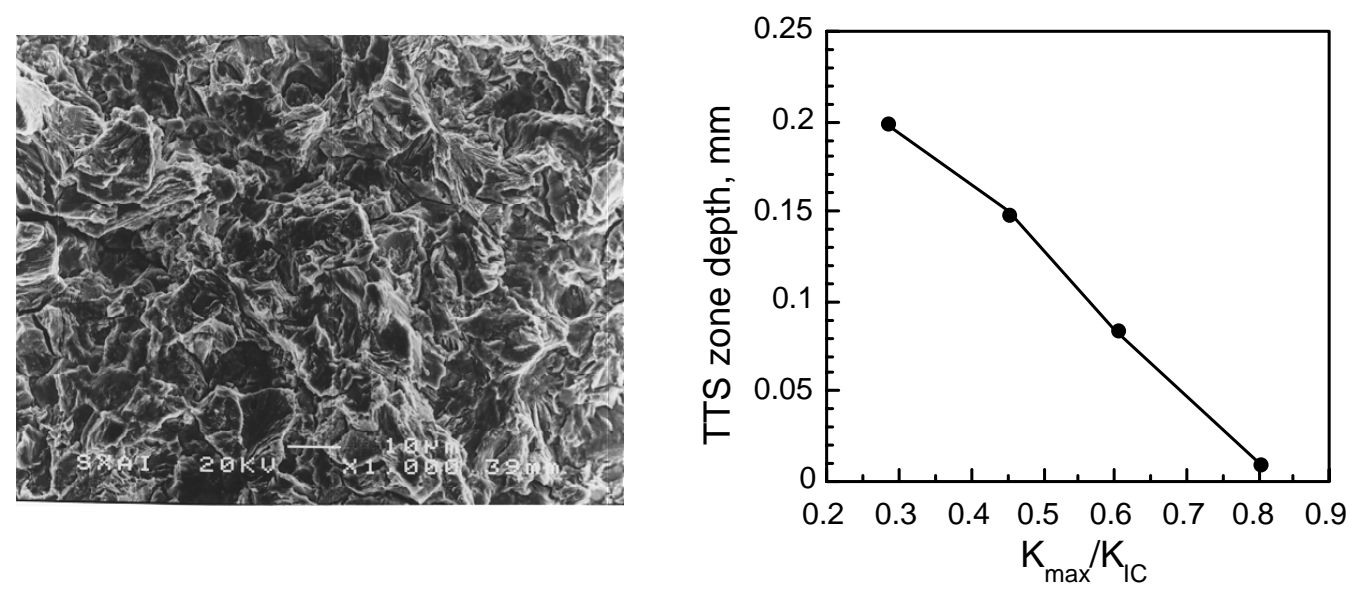

FIGURE 2. Fractographic appearance (left) and depth (right) of the TTS zone.

\section{Numerical modelling}

A numerical simulation was performed of the stress-strain state near the crack tip under plane-strain small-scale yielding in an elastoplastic material with combined isotropickinematic strain-hardening. Its characteristics are those of the steel used in the experiments (cf. Table 2). The crack was modelled as a round-tip slit with initial height (twice the tip radius) of $5 \mu \mathrm{m}$ in agreement with experimental data for fatigue cracks in high-strength steels. The loading history consisted of ten loading cycles in accordance with most 
experimental fatigue programmes $\left(\mathrm{K}_{\max } / \mathrm{K}_{\mathrm{IC}}=0.45,0.60\right.$ and $\left.0.80 \mathrm{~K}_{\mathrm{IC}}\right)$, and rising load corresponding to the HAC test. The nonlinear finite element code was used with updated Lagrangian formulation.

Two crack tip plastic zones are of interest: (i) forward or monotonic plastic zone, defined as the domain suffering plastic strain at load maxima $\left(\mathrm{K}=\mathrm{K}_{\max }\right)$; (ii) reversed or cyclic plastic zone, region where plasticity takes place at load minima $\left(\mathrm{K}=\mathrm{K}_{\min } \cong 0\right)$. The finite element analysis provides the following estimation of the depth of the forward (monotonic) plastic zone at $K_{\max }$ (defined by the equivalent von Mises stress $\sigma_{\mathrm{eq}} \geq \sigma_{\mathrm{Y}}$, where $\sigma_{\mathrm{Y}}$ is the tensile yield stress, cf. Table 2):

$$
\mathrm{X}_{\mathrm{Y}}\left(\mathrm{K}_{\max }\right)=0.0335\left(\mathrm{~K}_{\max } / \sigma_{\mathrm{Y}}\right)^{2}
$$

The reversed (cyclic) plastic zone at $\mathrm{K}_{\min } \cong 0$ is also dependent on the previous $\mathrm{K}_{\text {max }}$-level (i.e., on the range $\Delta \mathrm{K}$ ). Because of the material's hardening, it is natural to define the plastic flow zone at cyclic loading from the condition of positive increment of the equivalent plastic strain $\left(\mathrm{d} \varepsilon_{\mathrm{eq}}, \mathrm{p}>0\right)$. This is the active, really cyclic, plastic zone. For cyclic loading under given $K_{\max }$, the depth of this reversed (cyclic) plastic zone at unloading $\left(\mathrm{K}=\mathrm{K}_{\min }\right)$ may be estimated as:

$$
\mathrm{x}_{\Delta}\left(\mathrm{K}_{\max }\right)=0.0065\left(\mathrm{~K}_{\max } / \sigma_{\mathrm{Y}}\right)^{2}
$$

The rising load HAC test after fatigue precracking involves three phases, each of one characterised by its K-level and the active plastic zone (APZ) size: (i) initial phase associated with elastic unloading in the near-tip region and no plasticity; (ii) intermediate phase beginning at $\mathrm{K} \approx 0.2 \mathrm{~K}_{\max }$ and finishing at $\mathrm{K}=\mathrm{K}_{\max }$ during which the APZ is the straindefined one (reversed or cyclic plastic zone of depth $\mathrm{x}_{\Delta}$ ); (iii) final phase $\mathrm{K}>\mathrm{K}_{\max }$ during which the APZ is the stress-defined one (forward or monotonic plastic zone of depth $\mathrm{x}_{Y}$ ). Thus the APZ depth $\mathrm{x}_{\perp}$ is:

$$
\mathrm{x}_{\perp}(\mathrm{K})=\text { Fel! (3) }
$$

and this evolution of APZ is given in Fig. 3 after precracking with $\mathrm{K}_{\max }=0.60 \mathrm{~K}_{\mathrm{IC}}$.
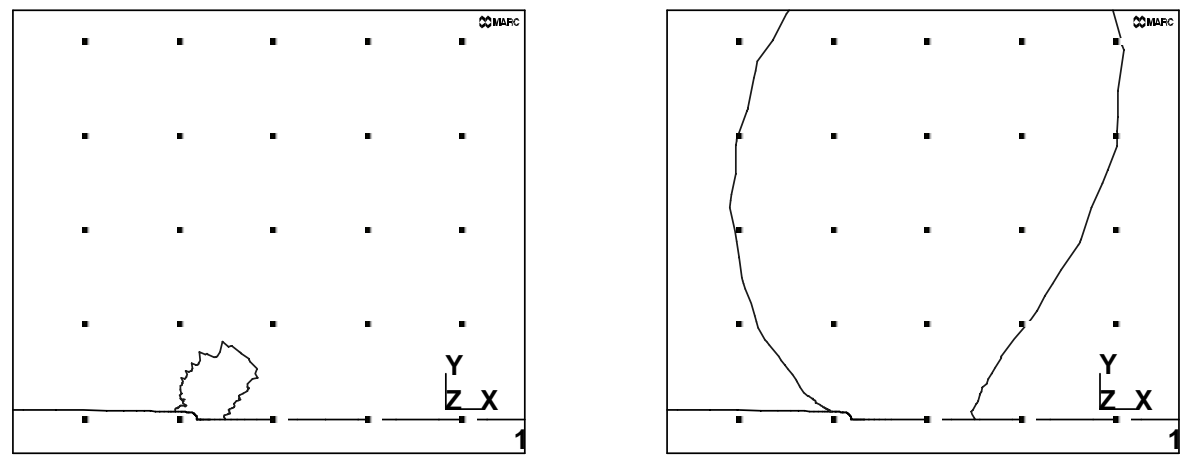

FIGURE 3. Sudden increase ("explosion") of the active plastic zone (APZ) caused by the change from the reversed or cyclic plastic zone (strain-defined one of depth $\mathrm{x}_{\Delta}$ ) to the forward or monotonic plastic zone (stress-defined one of depth $\mathrm{x}_{\mathrm{Y}}$ ) when the applied K-level exceeds the historical maximum $\mathrm{K}_{\max }$ (fatigue precracking with $\mathrm{K}_{\max } / \mathrm{K}_{\mathrm{IC}}=0.60$ ).

\section{Discussion}

The critical SIF for HAC is $\mathrm{K}_{\mathrm{QHAC}}=\left[\mathrm{F}_{\mathrm{HAC}} / \mathrm{F}_{\mathrm{C}}\right] \mathrm{K}_{\mathrm{IC}}$ (air), cf. Fig. 1 and Table 2. Fig. 4 offers the computed plastic zone sizes during fatigue precracking (monotonic at $\mathrm{K}=\mathrm{K}_{\max }$ and cyclic at $\mathrm{K}=\mathrm{K}_{\min } \cong 0$ ) and at the end of the HAC tests. For lower precracking $\mathrm{K}_{\text {max }}$-levels, $\mathrm{K}_{\mathrm{QHAC}}>$ 
$\mathrm{K}_{\max }$ and the active plastic zone at fracture is the monotonic one $\mathrm{x}_{\mathrm{Y}}$, whereas for the strongest fatigue regimes (higher levels of $\mathrm{K}_{\max }=0.80 \mathrm{~K}_{\mathrm{IC}}$ ) $\mathrm{K}_{\mathrm{QHAC}}$ does not exceed $\mathrm{K}_{\max }$ and the advance of plastic straining is confined to the cyclic plastic zone $\mathrm{x}_{\Delta}$ (where cyclic plastic flow takes place). Just when the applied $\mathrm{K}$ level in a HAC test overpasses the fatigue precracking level $\left(\mathrm{K}>\mathrm{K}_{\max }\right)$, the active plastic zone changes from strain- to stress-defined, i.e., from cyclic to monotonic, and this change produces a sudden increase of plastic zone size (an "explosion" of plastic zone).

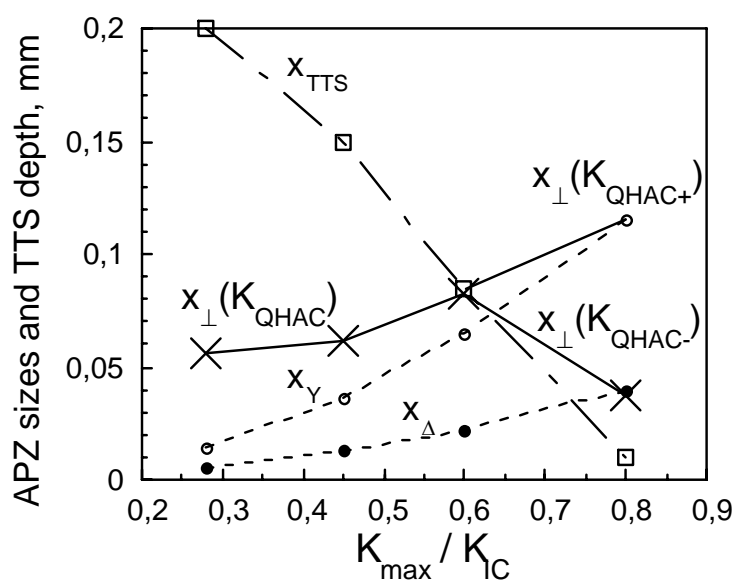

FIGURE 4. TTS zone depth and sizes of the monotonic $\left(\mathrm{K}=\mathrm{K}_{\max }\right)$ and cyclic $\left(\mathrm{K}=\mathrm{K}_{\min } \cong 0\right)$ plastic during fatigue and at the end of the HAC tests $\mathrm{K}=\mathrm{K}_{\mathrm{QHAC}}{ }^{-}$(left-limit) and $\mathrm{K}=\mathrm{K}_{\mathrm{QHAC}}{ }^{+}$ (right-limit). Only for tests after precracking with $\mathrm{K}_{\max }=0.80 \mathrm{~K}_{\mathrm{IC}}$ there is a difference between $\mathrm{K}_{\mathrm{QHAC}}{ }^{-}$and $\mathrm{K}_{\mathrm{QHAC}}{ }^{+}$.

In the plot of Fig. 4 the afore-said "explosion" of the plastic zone is represented by two curves of $\mathrm{x}_{\perp}$ at $\mathrm{K}_{\mathrm{QHAC}}{ }^{-}$(the level $\mathrm{K}_{\mathrm{QHAC}}$ is approached from the left, i.e., $\mathrm{K}$ tends to $\mathrm{K}_{\mathrm{QHAC}}$ but does not exceed it) and $\mathrm{K}_{\mathrm{QHAC}}{ }^{+}$(the level $\mathrm{K}_{\mathrm{QHAC}}$ is approached from the right, i.e., $\mathrm{K}$ just exceeds $\left.\mathrm{K}_{\mathrm{QHAC}}\right)$. This difference only applies to the tests with the strongest fatigue precracking programme in which the fatigue precracking level is not surpassed during the HAC test, since this finishes just at that level, i.e., at the moment of the sudden increase of plastic zone size, and thus the final plastic zone could be associated with $\mathrm{K}_{\mathrm{QHAC}}{ }^{-}$or with $\mathrm{K}_{\mathrm{QHAC}}{ }^{+}$, (experimental scatter) although in the main part of the test the plastic zone is confined to its reduced cyclic value $\mathrm{x}_{\Delta}$ associated with the fatigue precracking period.

The TTS has no relationship with the plastic zone, and the opposite trend which exhibit these two magnitudes seems to indicate that the potential role of dislocations in hydrogen transport is reduced by enhancing the trapping of hydrogen instead of transporting it over long penetration distances. This is consistent with experimental observations by Zakroczymski [11] of the effects of plastic deformation on hydrogen transport in iron, nickel and stainless steel which did not support the assumption that moving dislocations accelerate hydrogen transport.

The assumption of increasing trapping of hydrogen as a consequence of fatigue pecracking is consistent with the predamage in the plastic zone created by fatigue (cyclic plastic zone of the size $\mathrm{x}_{\Delta}$ ) which delays the hydrogen entry by an increase of the dislocation density an thus of the number of potential traps for hydrogen. The experimental fact of better HAC performance for increased $K_{\max }$ level (Fig. 1) can also be explained by this phenomenon of trapping. 


\section{Conclusions}

It is shown that cyclic crack-tip plasticity improves the HAC behaviour of the steel, since the failure load in hydrogen is an increasing function of the maximum stress intensity factor during the last stage of fatigue precracking.

Fractographic analysis showed that the micro-damage produced by the hydrogen was clearly detectable by scanning electron microscopy, through a specific microscopic topography associated with hydrogen effects: tearing topography surface or TTS.

When cyclic (fatigue) loading is applied during precracking, the active plastic zone changes from the forward or monotonic one (stress-defined ) at the maximum load to the reversed or cyclic one (strain-defined) at the minimum load. When the applied level of loading exceeds the historical maximum, a sudden increase ("explosion") of the active plastic zone takes place.

In the majority of cases, the hydrogen affected region exceeds the plastic zone, i.e., the only region in which there is dislocation movement, so that hydrogen transport cannot be attributed to dislocation dragging, but only to a random-walk diffusion. It is stress-assisted diffusion, according to which hydrogen is driven by the hydrostatic stress gradient.

The beneficial effect of crack tip plastic straining over the HAC is due to the delay of hydrogen entry caused by compressive residual (hydrostatic) stress after precracking and by enhanced trapping of hydrogen as a consequence of plastic straining, which increases the dislocation density in the vicinity of the crack tip.

\section{Acknowledgements}

The authors wish to thank the financial support of this work by the following institutions: Spanish Ministry for Scientific and Technological Research MCYT-FEDER (Grant MAT2002-01831), FEDER-INTERREG III (Grant RTCT-B-Z/SP2.P18), Junta de Castilla y León (JCYL; Grant SA078/04) and Spanish Foundation "Memoria de D. Samuel Solórzano Barruso". In addition, the authors wish to thank EMESA TREFILERIA S.A (La Coruña, Spain) for providing the steels used in the experimental programme.

\section{References}

1. Troiano, A.R., Transactions of the ASM, vol. 52, 54-80, 1960.

2. Van Leeuwen, H.-P. Engng. Fracture Mech., vol. 6, 141-161, 1974.

3. Toribio, J. and Kharin, V., Fat. Fracture Engng. Mater. Struct., vol. 20, 729-745, 1997.

4. Tien, J.K., Thompson, A.W., Bernstein, I.M. and Richards, R.S., Metall. Trans., vol. 7A, 821-829, 1976.

5. Johnson, H.H. and Hirth, J.P., Metall. Trans., vol. 7A, 1543-1548, 1976.

6. Nair, S.V., Jensen, R.R. and Tien, J.K., Metall. Trans., vol. 14A, 385-393, 1983.

7. Toribio, J. and Lancha, A.M., J. Mater. Sci., vol. 31, 6015-6024, 1996.

8. Thompson, A.W. and Chesnutt, J.C., Metall. Trans., vol. 10A, 1193-1196, 1979.

9. Costa, J.E. and Thompson, A.W., Metall. Trans., vol. 13A, 1315-1318, 1982. 
ECF15

10. Toribio, J., Metall. Mater. Trans., vol. 28A, 191-197, 1997.

11. Zakroczymski, T., Corrosion, vol. 41, 485-489, 1985. 